\title{
Characterizing Health Outcomes in Idiopathic Pulmonary Fibrosis using US Health Claims Data
}

\author{
Kathleen M. Mortimer ${ }^{\mathrm{a}} \quad$ Dorothee B. Bartels ${ }^{\mathrm{b}}$ Nadine Hartmann ${ }^{\mathrm{c}}$ \\ Jorge Capapey ${ }^{d}$ Jing Yang ${ }^{e}$ Robert Gately ${ }^{a}$ Cheryl Enger ${ }^{\mathrm{e}}$ \\ ${ }^{a}$ Optum Epidemiology, Boston, MA, USA; ${ }^{b}$ Institute for Epidemiology, Social Medicine and Health Systems Research, \\ Hannover Medical School, Hannover, Germany; ' ${ }^{C}$ Boehringer Ingelheim International GmbH, Ingelheim, Germany;

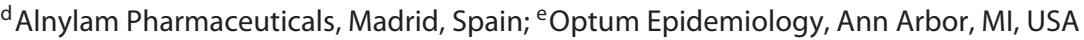

\section{Keywords}

Algorithms - Database - Idiopathic pulmonary fibrosis .

Incidence $\cdot$ Insurance, health

\begin{abstract}
Background: Idiopathic pulmonary fibrosis (IPF) is a lifethreatening interstitial lung disease (ILD). Characterizing health outcomes of IPF patients is challenging due to disease rarity. Objective: This study aimed to identify the burden of disease in patients newly diagnosed with IPF. Methods: Patients with $\geq 1$ claim with an IPF diagnosis were identified from a United States healthcare insurer's database (20002013). Patients with other known causes of ILD or aged $<40$ years were excluded. Subgroups were compared based on the 2011 change in International Classification of Diseases, 9th Revision (ICD-9) definition of IPF and occurrence of IPF testing. The prevalence and incidence of preselected health conditions of clinical interest were estimated. Results: Median age of newly diagnosed patients $(n=7,298)$ was 62 years (54.0\% male). Restricting to patients with IPF diagnostic testing did not substantially affect cohort characteristics, nor did ICD-9 IPF coding change. Mean follow-up was 1.7 years; $16.8 \%$ of patients died; and a substantial proportion of
\end{abstract}

\begin{tabular}{ll}
\hline KARGER & $\begin{array}{l}\text { ( ) 2020 The Author(s) } \\
\text { Published by S. Karger AG, Basel }\end{array}$ \\
$\begin{array}{l}\text { E-Mail karger@karger.com } \\
\text { www.karger.com/res }\end{array}$ & $\begin{array}{l}\text { This is an Open Access article licensed under the Creative Commons } \\
\text { Attribution-NonCommercial-4.0 International License (CC BY-NC) } \\
\text { (http://www.karger.com/Services/OpenAccessLicense), applicable to } \\
\text { the online version of the article only. Usage and distribution for com- } \\
\text { mercial purposes requires written permission. }\end{array}$ \\
3OPEN ACCESS &
\end{tabular}

patients were censored due to end of health plan enrollment (50.7\%) and other causes of ILD (19.6\%). The incidence of pulmonary hypertension, lung cancer, and claims-based algorithm proxy for acute respiratory worsening of unknown cause was 22.5, 17.6, and 12.6 per 1,000 person-years, respectively. Conclusions: Patients with IPF had a high disease burden with a variety of health outcomes observed, including a high rate of mortality. Database censoring due to changes in enrollment or other ILD diagnoses limited followup. Altering cohort entry definitions, including IPF testing or ICD-9 IPF coding change, had little impact on cohort baseline characteristics.
() 2020 The Author(s)

Published by S. Karger AG, Basel

\section{Introduction}

Idiopathic pulmonary fibrosis (IPF) is a rare, progressive, and life-threatening interstitial lung disease (ILD) of unknown etiology that leads to scarring of the lung $[1,2]$. It generally occurs in patients 50 years or older. Previ-

D.B.B. and J.C. were employees of Boehringer Ingelheim International $\mathrm{GmbH}$, Ingelheim, Germany at the time of study conduct. 
ously, lung transplantation was the only treatment considered to impact prognosis; however, few patients were eligible. Although pharmacotherapy has been approved for IPF in the United States (US) [3], a better understanding of the characteristics of patients with IPF is needed. The primary objective of this study was to characterize patients newly diagnosed with IPF, including prevalence and incidence estimates for selected health conditions of clinical interest.

\section{Methods}

\section{Cohort Identification}

Patients were drawn from the proprietary Optum Research Database, which contains eligibility, pharmacy, laboratory, and medical claims data from a large US commercial health plan between 1999 and 2013. This database is representative of the US's commercially insured population and has been used extensively for pharmacoepidemiology research, including postapproval safety studies [4-6].

Patients were required to have at least 1 medical claim with a diagnosis code of IPF between January 1, 2000, and December 31, 2013 , and to be aged 40 years or older. During the study period, International Classification of Diseases, 9th Revision (ICD-9) codes to identify IPF were modified. Prior to October 2011, the initial inclusion diagnosis code was ICD-9 516.3 (idiopathic interstitial pneumonia). Effective October 2011, the inclusion diagnosis code was ICD-9 516.31 (IPF). Patients with other known causes of ILD recorded during the 12 -month baseline period were excluded (online suppl. Table S1; for all online suppl. material, see www. karger.com/doi/10.1159/000504630) [7].

Patients in the newly diagnosed IPF cohort (IPF cohort) were required to have an index diagnosis of IPF within the study period (January 1, 2000 to December 31, 2013), with no IPF claims during the previous 12 months (the look-back period). A more restrictive definition was also used; patients with a procedure code related to testing for IPF during the 12-month look-back period prior to the IPF diagnosis date entered a subcohort (IPF subcohort). Procedures included either surgical lung biopsy (ICD-9 codes 33.28 and 34.21; Current Procedural Terminology codes 32602, 32607, $32608,32609,32095,32096,32097$, and 32100-32160) or highresolution computed tomography of the thorax (ICD-9 code 87.41; Current Procedural Terminology codes 71250, 71260, and 71270) [7].

Follow-up time extended from the cohort entry date until the earliest of the following: disenrollment from the health plan; death; a claim for another known cause of ILD (online suppl. Table S1); or the end of the study period.

\section{Outcome Measures}

Outcomes of clinical interest were identified by diagnosis and procedure codes, using either validated algorithms (when available) or clinical input and medical claims coding systems searches. To identify possible out-of-hospital deaths, claims data were linked to the Social Security Administration Death Master File that provides information on the occurrence (but not cause) of death for individuals aged 18 years and older.
Primary outcomes included a proxy measure of acute respiratory worsening of unknown cause (ARWUC) [8], pulmonary hypertension $(\mathrm{PH})[9]$, pulmonary arterial hypertension $(\mathrm{PAH})[9]$, lung transplantation, lung cancer $[10,11]$, acute myocardial infarction, and all-cause mortality. Secondary outcomes included gastrointestinal perforation [12], chronic renal failure/insufficiency [13-15], hemorrhagic diathesis or coagulopathy, venous thrombosis [16], pulmonary embolism [16], stroke, cardiac arrhythmia [17], congestive heart failure [18], ischemic heart disease [19, 20], arterial hypertension [21, 22], neutropenia [23], pneumonia [24], sepsis [25], chronic obstructive pulmonary disease [26, 27], gastroesophageal reflux disease (GERD) [28, 29], type 2 diabetes mellitus $[30,31]$, obstructive sleep apnea, bronchitis, upper respiratory infections, pulmonary rehabilitation, acute coronary syndrome, angina pectoris, and a series of bleeding events.

Only the first occurrence of each outcome during follow-up was counted; however, the occurrence of 1 type of outcome did not preclude counting the occurrence of a different type of outcome.

\section{Baseline Characteristics}

Selected baseline characteristics including primary and secondary outcome conditions (as listed above) and measures of healthcare utilization are given in Table 1 .

The study was approved by the New England Institutional Review Board (14-341).

\section{Statistical Methods}

Baseline characteristics were compared for patients diagnosed before and after the ICD-9 coding changes for IPF diagnosis. Prevalence was calculated by dividing the number of patients in the cohort with the condition during the study period (January 1, 2000 to December 31, 2013; IPF cohort) or the 12-month look-back period (IPF subcohort) by the total number of patients in the database ("complete-period" population). Incidence rates (IRs [number of patients with the outcome divided by the sum of all observation time-to-events for all patients per cohort]) were calculated per 1,000 person-years (py). For each outcome, the IR during followup is presented only for patients with no evidence of this condition during baseline. Length of follow-up observed was summarized by reason for censoring.

Analyses were conducted using SAS version 9.2 (SAS Institute Inc., Cary, NC, USA).

\section{Results}

The median age of the IPF cohort $(n=7,298)$ was 62 years (interquartile range $55-72$ ); $54.0 \%$ were male and $72.3 \%$ were white. The most frequently observed baseline covariates were use of corticosteroids (34.3\%) and GERD therapies (31.2\%; Table 1). Within the IPF subcohort $(n=3,930), 93.1 \%$ had claims for high-resolution computed tomography testing only, $0.8 \%$ had surgical lung biopsy claims only, and $6.1 \%$ had claims for both.

Restricting to patients with IPF diagnostic testing did not substantially affect cohort characteristics (Table 1). Characteristics of the IPF cohorts and subcohorts were 
Table 1. Characteristics of newly diagnosed IPF cohort and IPF subcohort (ORD cohort entry: January 1, 2000 to December 31, 2013)

\begin{tabular}{|c|c|c|}
\hline & $\begin{array}{l}\text { Overall IPF cohort } \\
(n=7,298)\end{array}$ & $\begin{array}{l}\text { IPF subcohort* } \\
(n=3,930)\end{array}$ \\
\hline \multicolumn{3}{|l|}{ Age, years (continuous) } \\
\hline Mean $(\mathrm{SD})$ & $63.2(11.6)$ & $62.7(11.1)$ \\
\hline \multicolumn{3}{|c|}{$\begin{array}{l}\text { Length of health plan membership prior to cohort entry } \\
\text { (continuous, months) }\end{array}$} \\
\hline \multicolumn{3}{|l|}{ Age, years, $n(\%)$} \\
\hline $40-44$ & $358(4.9)$ & $185(4.7)$ \\
\hline $45-49$ & $595(8.2)$ & $313(8.0)$ \\
\hline $50-54$ & $840(11.5)$ & $464(11.8)$ \\
\hline $55-59$ & $1,128(15.5)$ & $636(16.2)$ \\
\hline $60-64$ & $1,361(18.6)$ & $825(21.0)$ \\
\hline $65-69$ & $811(11.1)$ & $447(11.4)$ \\
\hline \multicolumn{3}{|l|}{ Gender, $n(\%)$} \\
\hline Male & $3,940(54.0)$ & $2,125(54.1)$ \\
\hline Female & $3,358(46.0)$ & $1,805(45.9)$ \\
\hline \multicolumn{3}{|l|}{ Geographic area, $n(\%)$} \\
\hline Northeast & $803(11.0)$ & $459(11.7)$ \\
\hline Midwest & $1,982(27.2)$ & $1,112(28.3)$ \\
\hline South & $3,551(48.7)$ & $1,856(47.2)$ \\
\hline West & $950(13.0)$ & $497(12.6)$ \\
\hline Unknown & $12(0.2)$ & $6(0.2)$ \\
\hline \multicolumn{3}{|l|}{ Race, $n(\%)$} \\
\hline White & $5,280(72.3)$ & $2,843(72.3)$ \\
\hline African American & $686(9.4)$ & $357(9.1)$ \\
\hline Hispanic/Latino & $387(5.3)$ & $214(5.4)$ \\
\hline Any corticosteroid & $2,504(34.3)$ & $1,579(40.2)$ \\
\hline $\mathrm{NAC}$ & $69(0.9)$ & $43(1.1)$ \\
\hline Azathioprine & $104(1.4)$ & $56(1.4)$ \\
\hline Cyclophosphamide & $55(0.8)$ & $43(1.1)$ \\
\hline Open lung biopsies & $171(2.3)$ & $171(4.4)$ \\
\hline Oxygen therapy & $1,181(16.2)$ & $734(18.7)$ \\
\hline \multicolumn{3}{|l|}{ GERD therapy (e.g., H2 receptor blockers, } \\
\hline proton pump inhibitors), $n(\%)$ & $2,276(31.2)$ & $1,341(34.1)$ \\
\hline Anticoagulation/antiplatelet therapy & $1,365(18.7)$ & $805(20.5)$ \\
\hline Amiodarone & $228(3.1)$ & $131(3.3)$ \\
\hline Bleomycin & $13(0.2)$ & $12(0.3)$ \\
\hline Nitrofurantoin & $230(3.2)$ & $128(3.3)$ \\
\hline Methotrexate & $49(0.7)$ & $29(0.7)$ \\
\hline Gold salts & $1(0.0)$ & $0(0.0)$ \\
\hline Epstein-Barr virus & $43(0.6)$ & $33(0.8)$ \\
\hline Hepatitis C & $217(3.0)$ & $131(3.3)$ \\
\hline Bronchial lavage & $367(5.0)$ & $334(8.5)$ \\
\hline
\end{tabular}

* Restricted to the IPF cohort with $\geq 1$ procedure related to testing for IPF during the 12-month baseline period. IPF, idiopathic pulmonary fibrosis; ORD, Optum Research Database; IQR, interquartile range; NAC, $N$-acetyl cysteine; GERD, gastroesophageal reflux disease. 
Table 2. Healthcare utilization characteristics of the newly diagnosed IPF cohorts during the 12-month baseline period (ORD cohort entry: January 1, 2000 to December 31, 2013)

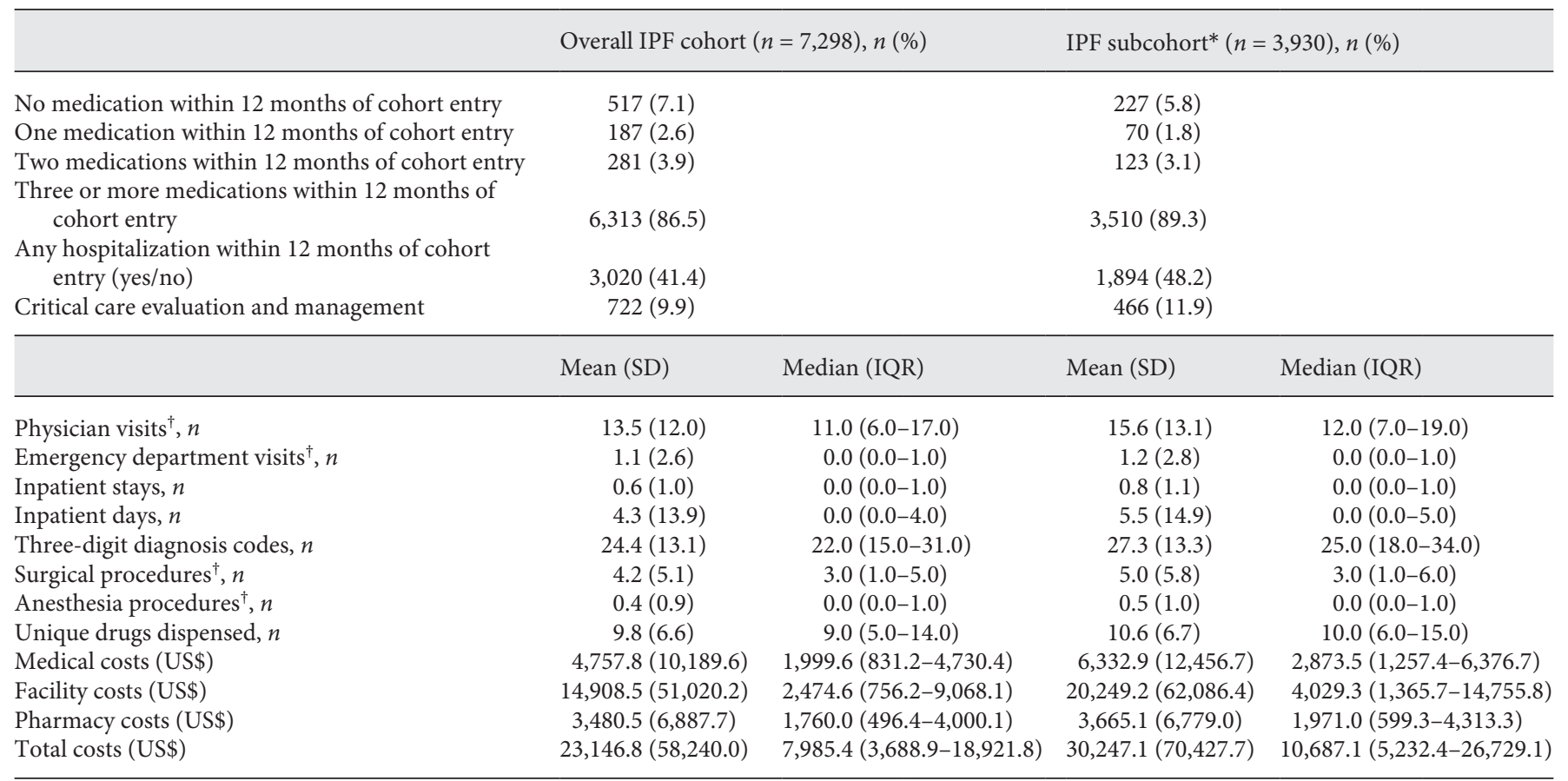

* Restricted to the IPF cohort with $\geq 1$ procedure related to testing for IPF during the 12 -month baseline period. ${ }^{\dagger}$ One counted per day. IPF, idiopathic pulmonary fibrosis; ORD, Optum Research Database; IQR, interquartile range; US, United States.

similar by cohort entry stratum (i.e., entry before October 2011 compared to entry during or after October 2011), although a higher proportion of patients with later cohort entry had corticosteroid use during baseline (42.8 vs. $33.3 \%$ [IPF cohort] and 48.9 vs. $39.1 \%$ [IPF subcohort]; data not shown). These differences notwithstanding, all remaining results are reported without stratification due to the similarity of other characteristics by cohort entry time.

Within the IPF cohort and IPF subcohort, 41.4 and $48.2 \%$ of patients were hospitalized during baseline and 86.5 and $89.3 \%$ had dispensings for at least 3 unique medications, respectively (Table 2).

Baseline prevalence of the primary outcome conditions was low, ranging from $0.3 \%(n=19)$ for PAH to $10.1 \%(n=739)$ for lung cancer (Table 3$)$. Among the secondary outcome conditions, prevalence ranged from $0.3 \%$ for gastrointestinal perforation to $55.3 \%$ for arterial hypertension (Table 3 ).

IRs of the nonfatal primary outcomes ranged from 2.1 per 1,000 py for PAH to 22.5 per 1,000 py for PH (Table 4). IRs for most outcomes were higher among the subcohort. Mortality was higher among the subcohort than the
IPF cohort (106.4 per 1,000 py vs. 97.1 per 1,000 py). Patients with baseline occurrence of an event were not considered at risk for the event during follow-up.

The median length of time from the index diagnosis until censoring was 1.0 years (interquartile range $0.3-2.5$; Table 5). For both the IPF cohort and subcohort, the most common reasons for censoring were the end of health plan enrollment (50.7 and $47.4 \%$, respectively) and other known causes of ILD (19.6 and $23.5 \%$, respectively). The most common censoring diagnoses were pulmonary eosinophilia (ICD-9 code 518.3: 21.8\%) and other specified alveolar and parietoalveolar pneumonopathies (ICD-9 code 516.8: 13.8\%; Table 6).

\section{Discussion/Conclusion}

This study used a large US healthcare insurance database to characterize health conditions among a cohort of patients with newly diagnosed IPF. Alternate cohort entry criteria were explored, including the requirement of claims for IPF testing and temporal changes in ICD diagnosis codes for IPF. The IPF cohort (diagnosis only) and 
Table 3. Prevalence of comorbidities as identified during the 12-month baseline period for the newly diagnosed IPF cohorts (ORD cohort entry: January 1, 2000 to December 31, 2013)

\begin{tabular}{|c|c|c|c|c|c|c|}
\hline & \multicolumn{3}{|c|}{ IPF cohort $(n=7,298)$} & \multicolumn{3}{|c|}{ IPF subcohort* $(n=3,930)$} \\
\hline \multicolumn{7}{|l|}{ Primary outcomes } \\
\hline Acute respiratory worsening of unknown cause & 122 & 1.7 & $1.4-2.0$ & 122 & 3.1 & $2.6-3.6$ \\
\hline Pulmonary hypertension & 172 & 2.4 & $2.0-2.7$ & 120 & 3.1 & $2.5-3.6$ \\
\hline Lung cancer & 739 & 10.1 & $9.4-10.8$ & 505 & 12.8 & $11.8-3.9$ \\
\hline Acute myocardial infarction & 124 & 1.7 & $1.4-2.0$ & 75 & 1.9 & $1.5-2.3$ \\
\hline \multicolumn{7}{|l|}{ Secondary outcomes } \\
\hline GI perforation & 19 & 0.3 & $0.1-0.4$ & 9 & 0.2 & $0.1-0.4$ \\
\hline Chronic renal failure/insufficiency & 832 & 11.4 & $10.7-12.1$ & 469 & 11.9 & $10.9-12.9$ \\
\hline Hemorrhagic diathesis or coagulopathy & 134 & 1.8 & $1.5-2.1$ & 89 & 2.3 & $1.8-2.7$ \\
\hline Congestive heart failure & 1,376 & 18.9 & $18.0-19.8$ & 789 & 20.1 & $18.8-21.3$ \\
\hline Ischemic heart disease & 1,930 & 26.4 & $25.4-27.5$ & 1,091 & 27.8 & $26.4-29.2$ \\
\hline Arterial hypertension & 4,036 & 55.3 & $54.2-56.4$ & 2,210 & 56.2 & $54.7-57.8$ \\
\hline Neutropenia & 126 & 1.7 & $1.4-2.0$ & 101 & 2.6 & $2.1-3.1$ \\
\hline Pneumonia & 555 & 7.6 & $7.0-8.2$ & 407 & 10.4 & $9.4-11.3$ \\
\hline Sepsis & 231 & 3.2 & $2.8-3.6$ & 153 & 3.9 & $3.3-4.5$ \\
\hline COPD & 2,753 & 37.7 & $36.6-38.8$ & 1,656 & 42.1 & $40.6-43.7$ \\
\hline GERD & 1,592 & 21.8 & $20.9-22.8$ & 978 & 24.9 & $23.5-26.2$ \\
\hline Type 2 diabetes mellitus & 1,638 & 22.4 & $21.5-23.4$ & 892 & 22.7 & $21.4-24.0$ \\
\hline Obstructive sleep apnea & 328 & 4.5 & $4.0-5.0$ & 204 & 5.2 & $4.5-5.9$ \\
\hline Bronchitis & 2,610 & 35.8 & $34.7-36.9$ & 1,533 & 39.0 & $37.5-40.5$ \\
\hline
\end{tabular}

* Restricted to the IPF cohort with $\geq 1$ procedure related to testing for IPF during the 12-month baseline period. IPF, idiopathic pulmonary fibrosis; ORD, Optum Research Database; GI, gastrointestinal; COPD, chronic obstructive pulmonary disease; GERD, gastroesophageal reflux disease.

subcohort (IPF testing prior to diagnosis) were similar, plausibly due to the fact that nearly half of the patients in the IPF cohort had an IPF testing procedure during baseline.

Slightly more patients were male $(54.0 \%)$, in contrast to the common perception that IPF is much more prevalent in men [1]. It is, however, consistent with findings summarized by the American Thoracic Society [32], suggesting a more balanced prevalence across genders at younger ages; nearly $70 \%$ of the study population was younger than 70 years old. Furthermore, other diseases that mimic IPF are more common in women, as reflected by the slightly larger proportion of female patients that was censored due to other causes of ILD ( 22 vs. $18 \%$; data not shown). During baseline, a substantial portion of patients had claims for "other and unspecified disorders of joints" (ICD-9 code 719: 25.2\%; data not shown) or "other disorders of soft tissue" (ICD-9 code 729: 25.7\%; data not shown), which were not in our initial exclusionary list. These patients may have had a nonspecific autoimmune disease that could be considered for exclusion in subsequent studies.

Direct comparisons to other studies are complicated by differences in cohort entry criteria, data sources, defi- 
Table 4. Frequency and incidence of primary and secondary outcomes among the newly diagnosed IPF cohort and subcohort during follow-up, restricted to patients without each condition during baseline (ORD cohort entry: January 1, 2000 to December 31, 2013)

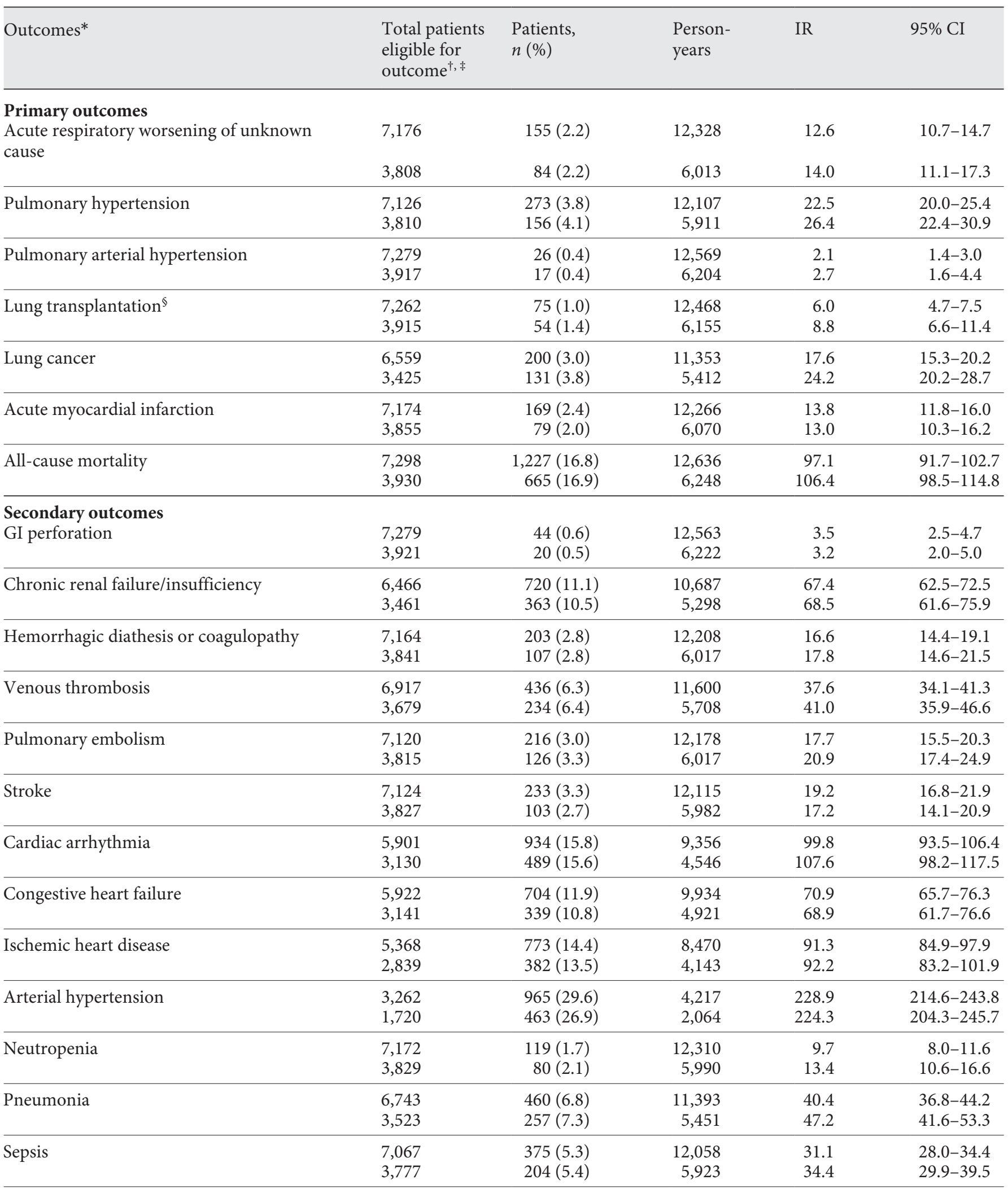


Table 4 (continued)

\begin{tabular}{|c|c|c|c|c|c|}
\hline Outcomes* & $\begin{array}{l}\text { Total patients } \\
\text { eligible for } \\
\text { outcome }^{\dagger, \ddagger}\end{array}$ & $\begin{array}{l}\text { Patients, } \\
n(\%)\end{array}$ & $\begin{array}{l}\text { Person- } \\
\text { years }\end{array}$ & IR & $95 \%$ CI \\
\hline GERD & $\begin{array}{l}5,706 \\
2,952\end{array}$ & $\begin{array}{r}1,032(18.1) \\
545(18.5)\end{array}$ & $\begin{array}{l}8,331 \\
3,997\end{array}$ & $\begin{array}{l}123.9 \\
136.3\end{array}$ & $\begin{array}{l}116.4-131.7 \\
125.1-148.3\end{array}$ \\
\hline Type 2 diabetes mellitus & $\begin{array}{l}5,660 \\
3,038\end{array}$ & $\begin{array}{l}545(9.6) \\
288(9.5)\end{array}$ & $\begin{array}{l}9,051 \\
4,462\end{array}$ & $\begin{array}{l}60.2 \\
64.5\end{array}$ & $\begin{array}{l}55.3-65.5 \\
57.3-72.4\end{array}$ \\
\hline Obstructive sleep apnea & $\begin{array}{l}6,970 \\
3,726\end{array}$ & $\begin{array}{l}368(5.3) \\
214(5.7)\end{array}$ & $\begin{array}{r}11,614 \\
5,699\end{array}$ & $\begin{array}{l}31.7 \\
37.5\end{array}$ & $\begin{array}{l}28.5-35.1 \\
32.7-42.9\end{array}$ \\
\hline Bronchitis & $\begin{array}{l}4,688 \\
2,397\end{array}$ & $\begin{array}{r}1,201(25.6) \\
601(25.1)\end{array}$ & $\begin{array}{l}6,396 \\
2,967\end{array}$ & $\begin{array}{l}187.8 \\
202.6\end{array}$ & $\begin{array}{l}177.3-198.7 \\
186.7-219.5\end{array}$ \\
\hline Pulmonary rehabilitation & $\begin{array}{l}7,270 \\
3,912\end{array}$ & $\begin{array}{l}43(0.6) \\
29(0.7)\end{array}$ & $\begin{array}{r}12,521 \\
6,176\end{array}$ & $\begin{array}{l}3.4 \\
4.7\end{array}$ & $\begin{array}{l}2.5-4.6 \\
3.1-6.7\end{array}$ \\
\hline Acute coronary syndrome & $\begin{array}{l}7,072 \\
3,802\end{array}$ & $\begin{array}{l}212(3.0) \\
108(2.8)\end{array}$ & $\begin{array}{r}11,979 \\
5,914\end{array}$ & $\begin{array}{l}17.7 \\
18.3\end{array}$ & $\begin{array}{l}15.4-20.2 \\
15.0-22.0\end{array}$ \\
\hline Angina pectoris & $\begin{array}{l}6,981 \\
3,753\end{array}$ & $\begin{array}{l}289(4.1) \\
141(3.8)\end{array}$ & $\begin{array}{r}11,580 \\
5,710\end{array}$ & $\begin{array}{l}25.0 \\
24.7\end{array}$ & $\begin{array}{l}22.2-28.0 \\
20.8-29.1\end{array}$ \\
\hline Bleeding & $\begin{array}{l}6,682 \\
3,582\end{array}$ & $\begin{array}{l}727(10.9) \\
372(10.4)\end{array}$ & $\begin{array}{r}10,488 \\
5,175\end{array}$ & $\begin{array}{l}69.3 \\
71.9\end{array}$ & $\begin{array}{l}64.4-74.5 \\
64.8-79.6\end{array}$ \\
\hline Major GI bleeding (upper) & $\begin{array}{l}7,206 \\
3,870\end{array}$ & $\begin{array}{r}108(1.5) \\
53(1.4)\end{array}$ & $\begin{array}{r}12,359 \\
6,100\end{array}$ & $\begin{array}{l}8.7 \\
8.7\end{array}$ & $\begin{array}{l}7.2-10.6 \\
6.5-11.4\end{array}$ \\
\hline Epistaxis & $\begin{array}{l}7,165 \\
3,848\end{array}$ & $\begin{array}{r}166(2.3) \\
95(2.5)\end{array}$ & $\begin{array}{r}12,169 \\
6,013\end{array}$ & $\begin{array}{l}13.6 \\
15.8\end{array}$ & $\begin{array}{l}11.6-15.9 \\
12.8-19.3\end{array}$ \\
\hline Hemorrhoids & $\begin{array}{l}7,120 \\
3,834\end{array}$ & $\begin{array}{l}215(3.0) \\
113(2.9)\end{array}$ & $\begin{array}{r}11,961 \\
5,896\end{array}$ & $\begin{array}{l}18.0 \\
19.2\end{array}$ & $\begin{array}{l}15.7-20.5 \\
15.8-23.0\end{array}$ \\
\hline Hemorrhoidal bleeding & $\begin{array}{l}7,267 \\
3,910\end{array}$ & $\begin{array}{l}49(0.7) \\
28(0.7)\end{array}$ & $\begin{array}{r}12,499 \\
6,168\end{array}$ & $\begin{array}{l}3.9 \\
4.5\end{array}$ & $\begin{array}{l}2.9-5.2 \\
3.0-6.6\end{array}$ \\
\hline Intracranial hemorrhage & $\begin{array}{l}7,264 \\
3,910\end{array}$ & $\begin{array}{l}54(0.7) \\
28(0.7)\end{array}$ & $\begin{array}{r}12,549 \\
6,196\end{array}$ & $\begin{array}{l}4.3 \\
4.5\end{array}$ & $\begin{array}{l}3.2-5.6 \\
3.0-6.5\end{array}$ \\
\hline
\end{tabular}

* Occurrence of one outcome did not preclude the occurrence of another, with the exception of all-cause mortality, which censored all further potential outcomes for a patient. ${ }^{\dagger}$ For each condition, patients (and associated person-time) who had that condition identified during baseline were not considered at risk for incident events and were excluded. ${ }^{*}$ For each condition, IPF cohort data presented in first row, IPF subcohort data presented in following row. ${ }^{\S}$ For lung transplantation, patients with unilateral lung transplantation during the baseline period could be "at-risk" to receive another unilateral lung transplantation during the follow-up period; however, double lung transplantations during the baseline would preclude subsequent "at-risk" person-time during the follow-up period.

IPF, idiopathic pulmonary fibrosis; ORD, Optum Research Database; IR, incidence rate per 1,000 person-years; GI, gastrointestinal; COPD, chronic obstructive pulmonary disease; GERD, gastroesophageal reflux disease. 
Table 5. Length of follow-up for the newly diagnosed IPF cohorts (ORD cohort entry: January 1, 2000 to December 31, 2013)

\begin{tabular}{|c|c|c|c|}
\hline \multirow[t]{2}{*}{ Cohorts } & & \multicolumn{2}{|c|}{ Length of follow-up, years } \\
\hline & & mean $(\mathrm{SD})$ & median (IQR) \\
\hline IPF cohort & $7,298(100.0)$ & $1.7(1.9)$ & $1.0(0.3-2.5)$ \\
\hline \multicolumn{4}{|l|}{ Reason for censoring } \\
\hline End of study period & $940(12.9)$ & $3.3(2.7)$ & $2.6(1.0-4.9)$ \\
\hline Death & $1,227(16.8)$ & $1.3(1.5)$ & $0.8(0.2-1.8)$ \\
\hline End of health plan enrollment & $3,702(50.7)$ & $1.8(1.7)$ & $1.2(0.5-2.5)$ \\
\hline Exclusion criteria observed & $1,429(19.6)$ & $1.0(1.4)$ & $0.4(0.1-1.3)$ \\
\hline IPF subcohort* & $3,930(100.0)$ & $1.6(1.8)$ & $0.9(0.3-2.3)$ \\
\hline \multicolumn{4}{|l|}{ Reason for censoring } \\
\hline End of study period & $479(12.2)$ & $3.1(2.7)$ & $2.5(1.0-4.6)$ \\
\hline Death & $665(16.9)$ & $1.2(1.4)$ & $0.7(0.2-1.6)$ \\
\hline End of health plan enrollment & $1,862(47.4)$ & $1.7(1.7)$ & $1.1(0.5-2.4)$ \\
\hline Exclusion criteria observed & $924(23.5)$ & $0.9(1.3)$ & $0.3(0.1-1.1)$ \\
\hline
\end{tabular}

* Restricted to the IPF cohort with $\geq 1$ procedure related to testing for IPF during the 12-month baseline period.

IPF, idiopathic pulmonary fibrosis; ORD, Optum Research Database; IQR, interquartile range.

Table 6. Diagnosis codes most frequently resulting in exclusion ${ }^{1}$ due to other causes of ILD during the follow-up period (ORD cohort entry: January 1, 2000 to December 31,2013$)^{2}$

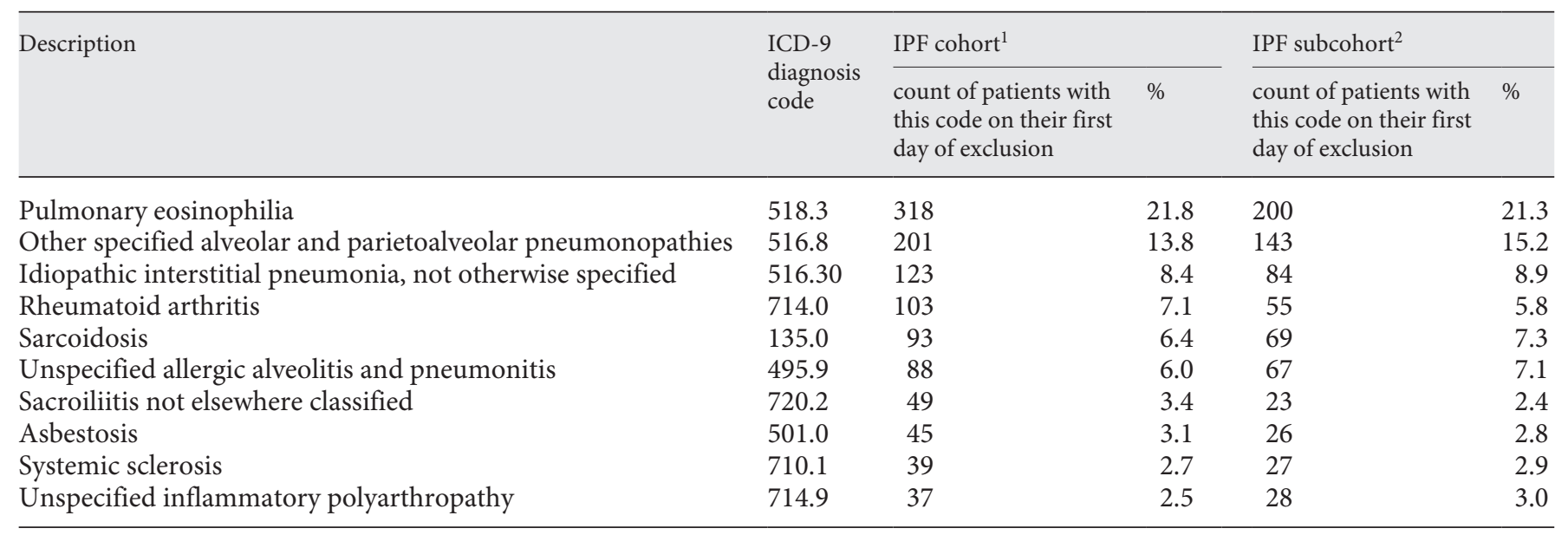

\footnotetext{
${ }^{1}$ Patients may have had claims with more than one qualifying diagnosis on the first day of exclusion, so the total does not match the cohort size. ${ }^{2}$ Restricted to the IPF cohort with $\geq 1$ procedure related to testing for IPF during the 12 -month baseline period.

ILD, interstitial lung disease; ORD, Optum Research Database; IPF, idiopathic pulmonary fibrosis.
}

nition of claims-based algorithms, and reliance on Social Security Administration information for death status. Nevertheless, the prevalence and incidence of many of the health conditions were lower than expected for an IPF population for several reasons. For example, claimsbased algorithms differ across studies and may not precisely identify true cases; also, sicker patients may migrate out of commercial health plans onto government insurance, and therefore their health outcomes are not observed in this database. Perhaps most importantly, other studies excluded patients diagnosed with other causes of ILD during some period of time after cohort entry [33]. Future events should not be used to define cohort entry criteria [34]. Rather, those patients should be censored at 
the time those exclusionary conditions are observed, whereas events and person-time accrual until that observed exclusion should be included in IR calculations. This may affect outcome IRs, as those patients contribute person-time to the denominator for all events prior to censoring.

In this study, $2.2 \%$ of the IPF cohort was observed to have an ARWUC episode during follow-up (IR: 12.6 per 1,000 py). The incidence of ARWUC is difficult to establish due to methodological variations between studies [35], and the numerous exclusionary comorbidities included in the definition (e.g., left heart failure, pulmonary embolism, and other identifiable causes of lung injury). In addition, dyspnea - an essential component of the clinical definition of acute exacerbations of IPF - may not be well captured in claims data, so this ARWUC algorithm is a proxy for clinically defined acute exacerbations and further validation is desirable. A retrospective study of 461 hospitalized patients with diagnosed IPF reported an annual incidence of $14.2 \%$ for clinically defined acute exacerbations [36]. However, the incidence of acute exacerbations in clinical trials is generally lower and may occur in $5-10 \%$ of patients with IPF per year [33].

Nearly $17 \%$ of patients died during follow-up ( 97.1 per 1,000 py), and a substantial percentage were censored for other reasons (19.6\% for other causes of ILD and 50.7\% due to end of health plan enrollment). However, from November 1, 2011, protected state records could no longer be disclosed; therefore, some deaths may not be available in the Death Master File, and mortality may be underestimated in this study. Among 622 patients randomized to placebo in the CAPACITY studies evaluating pirfenidone $(n=347)$ and the INSPIRE study evaluating interferon- $\gamma 1 \mathrm{~b}(n=275)$, the rate of claims-identified deaths due to all causes were $6.6 \%$ at 1 year and $13.7 \%$ at 2 years [37]. Similarly, during the 52 -week treatment period of the INPULSIS- 1 trial of nintedanib, $7.8 \%$ of patients in the placebo group died from any cause [38]. In a pooled analysis of the INPULSIS and TOMORROW trials, $8.3 \%$ of the patients in the placebo group died from any cause over 52 weeks [39]. However, drawing conclusions about the mortality of patients with IPF from clinical trial data is challenging. Patients in the "real-world," such as those in this study, tend to have more comorbidities, whereas those eligible for clinical trials tend to be fitter and are closely monitored, which may explain the lower death rates described above.

The percentage of patients with surgical lung biopsy (7\% of the IPF subcohort) is lower than the $34 \%$ value reported by Behr et al. [40]. Reported dispensings of com- mon IPF medications were also lower than expected. Many of these key medications are administered during inpatient stays, so utilization is not well captured in claims data due to the bundled payment mechanisms. Also, physician-provided samples and over-the-counter medications are not observed in claims data. Given that there were no efficacious or approved treatments available during these study periods, patients may have received additional healthcare and medications via clinical trials, which would not be observed in claims data.

This study has some key limitations. While claims data are extremely valuable to determine healthcare outcomes, claims databases have inherent limitations given the duration of follow-up, which can be restricted for example due to changes in health insurance enrollment. Particularly, severity of IPF could lead to disability or retirement, resulting in a shift to government insurance for some patients meaning outcomes that occur post-enrollment do not contribute to IRs. Also, the presence of a diagnosis code on a medical claim does not positively indicate the presence of disease, as diagnosis codes may be incorrect or included as rule-out criteria. This may be especially relevant in the current study due to the difficulty in diagnosing IPF when patients first present to the medical provider.

Validation by comparison to medical records may improve the accuracy of a claims-based algorithm for IPF case identification. Since these data were analyzed, 2 algorithms for the identification of patients with IPF in claims databases have been published. Each has limitations for application to the commercially insured population due to heavy weighting toward the elderly [41], and both have potentially low specificity [42].

The population in the Optum Research Database is representative of those commercially insured in the US; however, findings may be less generalizable to uninsured, publicly insured, older, or non-Caucasian populations. Lifestyle behaviors such as exercise, diet, smoking, and alcohol consumption are not captured in claims data and therefore cannot be described.

However, there are several advantages to this study. Unlike site- or registry-based studies that are typically limited in sample size, claims databases contain millions of lives, allowing for broader investigation of health outcomes within populations with rare conditions such as IPF. In addition, linkage of patient characteristics with pharmacy dispensings and medical encounters allows for more timely investigations and more completely captures the covered health services across the broad spectrum of healthcare providers. Defined health plan enrollment pe- 
riods provide specific person-time accrual, allowing the calculation of IRs. These factors contribute to both cost and time efficiencies, while maintaining study validity and avoiding selection, observation, or recall biases inherent in clinical trials.

Efforts were made to minimize other potential sources of bias. When available, validated algorithms were used to identify particular health conditions. Where validated algorithms were unavailable, a comprehensive approach to literature reviews and descriptive analyses was undertaken to correctly identify outcomes or comorbidities.

In conclusion, this study characterized patients newly diagnosed with IPF and showed that there are a variety of health conditions observable among these patients. The most prominent primary outcomes were mortality, $\mathrm{PH}$, and lung cancer, and for secondary outcomes, the highest IRs were observed for arterial hypertension, bronchitis, GERD, and chronic obstructive pulmonary disease. Alternate cohort entry definition, including IPF testing and changes in ICD-9 coding for IPF, had little impact on cohort baseline characteristics.

\section{Statement of Ethics}

Ethics approval was not required for this retrospective database analysis study.

\section{Disclosure Statement}

J.Y., R.G., and C.E. are employees of Optum Epidemiology. K.M.M. was an employee of Optum Epidemiology at the time the study was conducted. N.H. is an employee of Boehringer Ingelheim. D.B.B. and J.C. were employees of Boehringer Ingelheim at the time the study was conducted.

All authors meet criteria for authorship as recommended by the International Committee of Medical Journal Editors. The authors received no direct compensation related to the development of the manuscript. Editorial support was provided by Chester Trinick, BSc, of MediTech Media, a medical communications agency contracted and funded by Boehringer Ingelheim International $\mathrm{GmbH}(\mathrm{BI})$. BI was given the opportunity to review the manuscript for medical and scientific accuracy, as well as intellectual property considerations.

\section{Funding Sources}

This study was financially supported by Boehringer Ingelheim.

\section{Author Contributions}

This study was sponsored by a research contract between Optum and Boehringer Ingelheim. The authors were responsible for all content and editorial decisions, were involved in the study development, and approved the final version. As the guarantor of this work, Optum had full access to all the data in the study. As such, Optum takes responsibility for the integrity of the data, the accuracy of the data analysis and interpretation, and the final wording of the manuscript.

\section{References}

1 Fernández Pérez ER, Daniels CE, Schroeder DR, St Sauver J, Hartman TE, Bartholmai BJ, et al. Incidence, prevalence, and clinical course of idiopathic pulmonary fibrosis: a population-based study. Chest. 2010 Jan; 137(1):129-37.

2 Ley B, Collard HR, King TE Jr. Clinical course and prediction of survival in idiopathic pulmonary fibrosis. Am J Respir Crit Care Med. 2011 Feb;183(4):431-40.

3 Fala L. Ofev (Nintedanib): First tyrosine kinase inhibitor approved for the treatment of patients with idiopathic pulmonary fibrosis. Am Health Drug Benefits. 2015 Mar;8:101104.

4 Enger C, Jones ME, Kryzhanovskaya L, Doherty M, McAfee AT. Risk of developing diabetes and dyslipidemia among adolescents with bipolar disorder or schizophrenia. Int J Adolesc Med Health. 2013;25(1):3-11.

5 Enger C, Bennett D, Dawson KL, Aivado MA, Theodore D, McAfee AT. Hepatobiliary laboratory abnormalities among patients with chronic or persistent immune thrombocyto- penia (ITP). Ann Hepatol. 2011 Apr-Jun; 10(2):188-95

6 Enger C, Gately R, Ming EE, Niemcryk SJ, Williams L, McAfee AT. Pharmacoepidemiology safety study of fibrate and statin concomitant therapy. Am J Cardiol. 2010 Dec; 106(11):1594-601.

7 Raghu G, Chen SY, Yeh WS, Maroni B, Li Q, Lee YC, et al. Idiopathic pulmonary fibrosis in US Medicare beneficiaries aged 65 years and older: incidence, prevalence, and survival, 2001-11. Lancet Respir Med. 2014 Jul;2(7): 566-72.

8 Collard HR, Moore BB, Flaherty KR, Brown KK, Kaner RJ, King TE Jr, et al.; Idiopathic Pulmonary Fibrosis Clinical Research Network Investigators. Acute exacerbations of idiopathic pulmonary fibrosis. Am J Respir Crit Care Med. 2007 Oct;176(7): 636-43.

9 Kirson NY, Birnbaum HG, Ivanova JI, Waldman T, Joish V, Williamson T. Prevalence of pulmonary arterial hypertension and chronic thromboembolic pulmonary hypertension in the United States. Curr Med Res Opin. 2011 Sep;27(9):1763-8.

10 Cooper GS, Yuan Z, Stange KC, Dennis LK, Amini SB, Rimm AA. The sensitivity of Medicare claims data for case ascertainment of six common cancers. Med Care. 1999 May;37(5): 436-44.

11 McBean AM, Babish JD, Warren JL. Determination of lung cancer incidence in the elderly using Medicare claims data. Am J Epidemiol. 1993 Jan;137(2):226-34.

12 Curtis JR, Chen SY, Werther W, John A, Johnson DA. Validation of ICD-9-CM codes to identify gastrointestinal perforation events in administrative claims data among hospitalized rheumatoid arthritis patients. Pharmacoepidemiol Drug Saf. 2011 Nov;20(11): $1150-8$

13 Foley RN, Murray AM, Li S, Herzog CA, McBean AM, Eggers PW, et al. Chronic kidney disease and the risk for cardiovascular disease, renal replacement, and death in the United States Medicare population, 1998 to 1999. J Am Soc Nephrol. 2005 Feb;16(2):489-95. 
14 Winkelmayer WC, Schneeweiss S, Mogun H, Patrick AR, Avorn J, Solomon DH. Identification of individuals with CKD from Medicare claims data: a validation study. Am J Kidney Dis. 2005 Aug;46(2):225-32.

15 Collins AJ, Chen SC, Gilbertson DT, Foley $\mathrm{RN}$. CKD surveillance using administrative data: impact on the health care system. Am J Kidney Dis. 2009 Mar;53(3 Suppl 3):S27-36.

16 Tamariz L, Harkins T, Nair V. A systematic review of validated methods for identifying venous thromboembolism using administrative and claims data. Pharmacoepidemiol Drug Saf. 2012 Jan;21 Suppl 1:154-62.

17 Tamariz L, Harkins T, Nair V. A systematic review of validated methods for identifying ventricular arrhythmias using administrative and claims data. Pharmacoepidemiol Drug Saf. 2012 Jan;21 Suppl 1:148-53.

18 Saczynski JS, Andrade SE, Harrold LR, Tjia J, Cutrona SL, Dodd KS, et al. A systematic review of validated methods for identifying heart failure using administrative data. Pharmacoepidemiol Drug Saf. 2012 Jan;21 Suppl 1:129-40.

19 DiMartino LD, Hammill BG, Curtis LH, Gottdiener JS, Manolio TA, Powe NR, et al. External validity of the cardiovascular health study: a comparison with the Medicare population. Med Care. 2009 Aug;47(8):916-23.

20 Johnson ML, Petersen LA, Sundaravaradan R, Byrne MM, Hasche JC, Osemene NI, et al. The association of Medicare drug coverage with use of evidence-based medications in the Veterans Health Administration. Ann Pharmacother. 2009 Oct;43(10):1565-75.

21 Quan H, Khan N, Hemmelgarn BR, Tu K, Chen G, Campbell N, et al.; Hypertension Outcome and Surveillance Team of the Canadian Hypertension Education Programs. Validation of a case definition to define hypertension using administrative data. Hypertension. 2009 Dec;54(6):1423-8.

22 Dutro MP, Gerthoffer TD, Peterson ED, Tang SS, Goldberg GA. Treatment of hypertension and dyslipidemia or their combination among US managed-care patients. J Clin Hypertens (Greenwich). 2007 Sep;9(9):684-91.

23 Kim SY, Solomon DH, Liu J, Chang CL, Daniel GW, Schneeweiss S. Accuracy of identifying neutropenia diagnoses in outpatient claims data. Pharmacoepidemiol Drug Saf. 2011 Jul;20(7):709-13.

24 Cascini S, Agabiti N, Incalzi RA, Pinnarelli L, Mayer F, Arcà M, et al. Pneumonia burden in elderly patients: a classification algorithm using administrative data. BMC Infect Dis. 2013 Nov;13(1):559.

25 Carnahan RM, Herman RA, Moores KG. A systematic review of validated methods for identifying transfusion-related sepsis using administrative and claims data. Pharmacoepidemiol Drug Saf. 2012 Jan;21 Suppl 1:222-9.

26 Singh JA, Holmgren AR, Noorbaloochi S. Accuracy of Veterans Administration databases for a diagnosis of rheumatoid arthritis. Arthritis Rheum. 2004 Dec;51(6):952-7.

27 Blanchette CM, Dekoven M, De AP, Roberts M. Probabilistic data linkage: a case study of comparative effectiveness in COPD. Drugs Context. 2013 Oct;2013:212258.

28 Gosselin A, Luo R, Lohoues H, Toy E, Lewis $\mathrm{B}$, Crawley J, et al. The impact of proton pump inhibitor compliance on health-care resource utilization and costs in patients with gastroesophageal reflux disease. Value Health. 2009 Jan-Feb;12(1):34-9.

29 Halpern R, Kothari S, Fuldeore M, Zarotsky V, Porter V, Dabbous O, et al. GERD-related health care utilization, therapy, and reasons for transfer of GERD patients between primary care providers and gastroenterologists in a US managed care setting. Dig Dis Sci. 2010 Feb;55(2):328-37.

30 Rector TS, Wickstrom SL, Shah M, Thomas Greeenlee N, Rheault P, Rogowski J, et al. Specificity and sensitivity of claims-based algorithms for identifying members of Medicare+Choice health plans that have chronic medical conditions. Health Serv Res. 2004 Dec;39(6 Pt 1):1839-57.

31 Hebert PL, Geiss LS, Tierney EF, Engelgau MM, Yawn BP, McBean AM. Identifying persons with diabetes using Medicare claims data. Am J Med Qual. 1999 Nov-Dec;14(6): 270-7.

32 American Thoracic Society; European Respiratory Society. American Thoracic Society/ European Respiratory Society International Multidisciplinary Consensus Classification of the Idiopathic Interstitial Pneumonias. This joint statement of the American Thoracic Society (ATS), and the European Respiratory Society (ERS) was adopted by the ATS board of directors, June 2001 and by the ERS Executive Committee, June 2001. Am J Respir Crit Care Med. 2002 Jan;165(2):277-304.

33 Raghu G, Collard HR, Egan JJ, Martinez FJ, Behr J, Brown KK, et al.; ATS/ERS/JRS/ALAT Committee on Idiopathic Pulmonary Fibro- sis. An official ATS/ERS/JRS/ALAT statement: idiopathic pulmonary fibrosis: evidence-based guidelines for diagnosis and management. Am J Respir Crit Care Med. 2011 Mar; 183(6):788-824.

34 Lund JL, Horváth-Puhó E, Komjáthiné Szépligeti S, Sørensen HT, Pedersen L, Ehrenstein $\mathrm{V}$, et al. Conditioning on future exposure to define study cohorts can induce bias: the case of low-dose acetylsalicylic acid and risk of major bleeding. Clin Epidemiol. 2017 Nov;9: 611-26.

$35 \mathrm{Kim}$ DS. Acute exacerbations in patients with idiopathic pulmonary fibrosis. Respir Res. 2013 Aug;14(1):86.

36 Song JW, Hong SB, Lim CM, Koh Y, Kim DS. Acute exacerbation of idiopathic pulmonary fibrosis: incidence, risk factors and outcome. Eur Respir J. 2011 Feb;37(2):356-63.

37 King TE Jr, Albera C, Bradford WZ, Costabel U, du Bois RM, Leff JA, et al.; Implications for the Design and Execution of Clinical Trials. All-cause mortality rate in patients with idiopathic pulmonary fibrosis. Implications for the design and execution of clinical trials. Am J Respir Crit Care Med. 2014 Apr;189(7):82531.

38 Richeldi L, du Bois RM, Raghu G, Azuma A, Brown KK, Costabel U, et al.; INPULSIS Trial Investigators. Efficacy and safety of nintedanib in idiopathic pulmonary fibrosis. N Engl J Med. 2014 May;370(22):2071-82.

39 Richeldi L, Cottin V, du Bois RM, Selman M, Kimura T, Bailes Z, et al. Nintedanib in patients with idiopathic pulmonary fibrosis: combined evidence from the TOMORROW and INPULSIS $\left({ }^{\circledR}\right)$ trials. Respir Med. 2016 Apr;113:74-9.

40 Behr J, Kreuter M, Hoeper MM, Wirtz H, Klotsche J, Koschel D, et al. Management of patients with idiopathic pulmonary fibrosis in clinical practice: the INSIGHTS-IPF registry. Eur Respir J. 2015 Jul;46(1):186-96.

41 Esposito DB, Lanes S, Donneyong M, Holick CN, Lasky JA, Lederer D, et al. Idiopathic pulmonary fibrosis in United States automated claims. Incidence, prevalence, and algorithm validation. Am J Respir Crit Care Med. 2015 Nov $15 ; 192(10): 1200-7$

42 Ley B, Urbania T, Husson G, Vittinghoff E, Brush DR, Eisner MD, et al. Code-based diagnostic algorithms for idiopathic pulmonary fibrosis. Case validation and improvement. Ann Am Thorac Soc. 2017 Jun;14(6): $880-7$. 